\title{
Pola Kemitraan pada Pembangunan Prasarana dan Sarana Dasar Permukiman Kumuh di Kelurahan Kenjeran Surabaya Timur
}

\author{
Kusumastuti \\ Staf Pengaj ar Program Studi D-III Teknik Sipil FTSP. ITS. \\ email: kusumastuti@ce.its.ac.id
}

\begin{abstract}
ABSTRAK
Pembangunan prasarana dan sarana dasar merupakan salah satu beban yang mengiringi pertumbuhan kota-kota besar termasuk Surabaya. Wilayah Metroplitan Surabaya mengalami pula permasalahan, baik dalam penyediaan maupun pemanfaatan dan pemeliharaan prasarana / sarana dasar, terutama di lingkungan permukiman kumuh. Hal tersebut telah menjadi perhatian dalam program-program pembangunan perkotaan.

Dalam hal ini kelurahan Kenjeran Surabaya telah menerima bantuan program-program pembangunan perkotaan melalui KIP.(Pelita I, II, III), JPS., KIP. Komprehensif Tahun 1998. 2000,2002 , 2003. Akibat dari bantuan program-program tersebut, masyarakat makin mengandalkan pada bantuan yang disediakan atau mau diberi dengan berbagai kemudahan dari pemerintah. Untuk memperbaiki kendala tersebut diatas, maka diperlukan "Pola Kemitraan", sehingga masyarakat diharapkan dapat lebih terlibat dan bertanggung jawab dalam pembangunan lingkungan permukimannya.

Metoda pembahasan yang digunakan didalam penelitian ini adalah metode "deduksiteoritik-paradigmatik", yakni dengan mendeduksi "premis-premis kemitraan" yang tertuang didalam dokumen Habitat II dan membawanya ke dataran teoritik dan paradigmatik. Alasan mengenai pentingnya konsep kemitraan adalah untuk menjembatani gap antara pemerintah dan swasta, dan antara kepentingan komersial dan kepentingan masyarakat.
\end{abstract}

Kata kunci: Pola Kemitraan, Prasarana dan Sarana Dasar, Masyarakat.

\section{PENDAHULUAN}

Sarana dan Prasarana Umum pada dasarnya mudah dijumpai di kelurahan Kenjeran. Angkutan umum seperti bemo juga dapat dipakai untuk menjangkaunya. $\mathrm{Hal}$ ini memang layak diperhatikan, mengingat angkutan tersebut menghubungkan kota dengan wilayah wisata pantai yang ada di Kenjeran dan sebagai salah satu potensi yang mendukung aktifitas ekonomi masyarakat Kenjeran. Selain itu terdapat sentra perdagangan dan industri kecil.

Permasalahan yang ada di kelurahan Kenjeran adalah :

- Partisipasi dan keterbukaan warga dalam mendiskripsikan permasalahan yang ada masih rendah.

- Kepedulian warga terhadap kebersihan lingkungan masih rendah.

- Terdapat beberapa bantuan program seperti KIP.(Pelita I,II,III), JPS., KIP. Komprehensif Tahun 1998, 2000, 2002, 2003; yang pernah didapatkan warga kelurahan Kenjeran, tetapi dalam pelaksanaannya mayoritas terlambat serta tidak berkelanj utan.
- Koperasi serba Usaha yang bernama Muara Usaha saat ini sudah tidak aktif lagi.

Hal ini perlu diperbaiki, apabila masyarakat diharapkan lebih terlibat dan bertanggung jawab terhadap lingkungan permukimannya. Pola kemitraan sebenarnya melanjutkan pola yang sudah ada, yaitu yang berasal dari bantuan program-program yang telah diterima di kelurahan Kenjeran, hanya yang perlu diperbaiki adalah gap antara kepentingan komersial dan kepentingan masyarakat; hubungan antara pemerintah, swasta, masyarakat dan mediator, dilihat sebagai hubungan yang rekonsiliatif, karena masing-masing memiliki peran khusus dan tetap dihormati otonominya; setiap individu harus bertanggung jawab terhadap keberlanjutan lingkungan permukimannya; menghindari komunikasi dari hubungan yang hirarkikal (berjenjang), karena bentuk semacam ini cenderung menciptakan bentuk-bentuk eksploitasi; harus dilandasi oleh semangat berkontribusi bersama dan tidak dimanipulasi menjadi indoktrinasi dan pemaksaan ide. 


\section{TUJ UAN PENELITIAN}

1. Memperbaiki kesenjangan antara kepentingan komersial dan kepentingan masyarakat.

2. Meningkatkan kesadaran masyarakat yang lebih luas didalam pembangunan lingkungan permukiman.

3. Merubah visi masyarakat yang semula dilayani (obyek) menuju ke masyarakat sebagai pelaku (subyek) pembangunan lingkungan permukiman.

\section{LANDASAN TEORI}

\subsection{Konsep Dasar Kemitraan}

Konsep kemitraan didalam GSS (Global Strategy for Shelter) tahun 1990, secara eksplisit belum dinyatakan didalamnya. Namun indikasi kearah pentingnya konsep tersebut sudah tampak didalam alinea keenam dari Basic Principles of the GSS. Enam tahun kemudian konsep kemitraan perlu ditekankan sebagai salah satu konsep unggulan. Penekanan ini tampak pada Deklarasi Istambul (Habitat II) nomor 12, didalam bagian dari Report of United Conference on Human Settlements (UNCHS, 1996: 9, 13, 20).

\subsection{Tri Bina Plus}

Menurut laporan akhir kegiatan (2003:II-11). Tri Bina Plus mencakup pengembangan sumber daya manusia, pengembangan usaha kecil dan menengah, peningkatan kondisi fisik lingkungan yang dikembangkan untuk masing-masing kampung ditambah asas integrasi kampung didalam system pembangunan

\section{METODE PENELITIAN \\ 4.1. Studi Pendahuluan}

Pada tahap studi pendahuluan ini dilakukan studi terhadap data program-program yang pernah dilaksanakan di Kenjeran, seperti KIP.(Kampung Improvement Program), JPS. (J aring Pengaman Sosial - P3P, P2KP, PDM-DKE), dan KIP.Komprehensif Tahun 1998, 2000, 2002, 2003.

\subsection{Populasi dan Sampel}

Kesahihan prosedur-prosedur inferensi parametric misalnya bergantung pada bentuk-bentuk fungsi asal sample yang dianalisis. Dalam model-model penelitian yang bersifat probabilitas untuk menerangkan struktur populasi dengan mengasumsi kondisi-kondisi tertentu. Apabila sample dari populasi yang tidak diketahui, maka peneliti harus menggunakan metoda keselarasan untuk menentukan seberapa jauh sample yang diamati sesuai dengan model tertentu yang akan digunakan.

Menurut Kartono (1996:135) untuk populasi 10-100 orang diambil $100 \%$ Mengingat populasi dibawah 100 orang diambil 100\%

\subsection{Teknik Pembahasan Masalah}

Metoda pembahasan masalah yang digunakan adalah metode "deduksi-teoritikparadigmatik", yakni mendeduksi premispremis kemitraan yang tertuang didalam Habitat II dan membawanya kedataran teoritik dan paradigmatic, sehingga diperoleh pola kemitraan yang dapat memperbaiki kelemahan dari pola-pola program sebelumnya di kelurahan Kenjeran.

5. GAMBARAN UMUM KELURAHAN KENJ ERAN 5.1. Wilayah dan Geografis

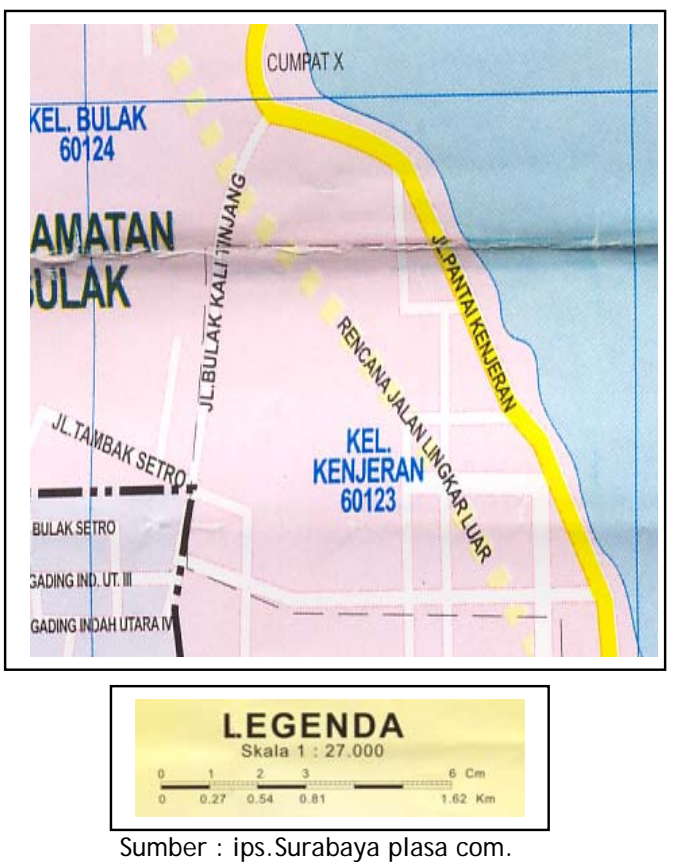

PETA LOKASI KELURAHAN KENJ ERAN 
Lokasi kampung kelurahan Kenjeran terletak disebelah Timur Laut kota Surabaya, termasuk dalam wilayah kecamatan Bulak dan juga termasuk dalam wilayah Surabaya Timur.

Adapun luas wilayah kelurahan Kenjeran \pm $71,551 \mathrm{Ha}$. Sebagian besar wilayahnya Iahan tambak dan lahan pesisir pantai. Wilayah tersebut dihuni oleh 741 keluarga dan jumlah penduduknya \pm 3453 orang. Permukiman di kelurahan Kenjeran terdiri atas Perumahan Real Estate Pantai Mentari dan Perumahan kampung. Perkampungan ada di lokasi wilayah RW 1 s/d Rw 4; sedangkan Perumahan Real Estate Pantai Mentari ada di wilayah RW 5.

Batas administrasi kelurahan Kenjeran adalah :

- Sebelah Utara : Kelurahan Kedung Cowek.

- Sebelah Selatan: Kelurahan Kompleks Kenjeran (AURI).

- Sebelah Timur : Kelurahan Kompleks Kenjeran.

- Sebelah Barat : Kelurahan Sukolilo.

\subsection{Kondisi Umum Fisik Kelurahan Kenjeran}

a. Aspek Ekonomi :

- Mayoritas masyarakat di wilayah RW 1 s/d RW 4 termasuk golongan menengah ke bawah, sedangkan masyarakat di wilayah RW 5 termasuk golongan menengah ke atas. Jenis pekerjaan penduduknya mayoritas nelayan dan swasta (pedagang).

b. Aspek Sosial :

- Tingkat pendidikan mayoritas lulusan SLTA.

- Tingkat kesehatan cukup baik.

- Kegiatan kampung yang menonjol : kegiatan PKK; Karang Taruna; Kerja bakti; dan Pengajian Bapak-bapak, Ibu-ibu serta Remaja.

- Asal penduduk : mayoritas dari J awa dan lebih kurang 30\% adalah dari Madura.

c. Aspek Budaya :

- Penduduk mayoritas beragama Islam, sering mengadakan pengajian yang terbagi atas kelompok remaja; kelompok ibu-ibu dan kelompok bapak-bapak.

\section{d. Aspek Prasrana dan Sarana :}

- Sirkulasi : Penghubung antar wilayah RW ada jalan aspal yang kondisinya tidak baik. Di gang-gang yang ada di RW $1 \mathrm{~s} / \mathrm{d}$ RW 4 mayoritas dengan lebar jalannya kira-kira 2 meter dilengkapi got (0,3 meter) dikedua sisi gang, yang semuanya sudah diplester (rabat beton) dengan kondisi yang tidak baik.

- Ruang Terbuka : mayoritas masih berwujud tambak-tambak dan pesisir pantai. Ruang terbuka juga ada dilokasi Rekreasi Pantai Kenjeran, yang dimanfaatkan untuk parkir pengunj ung.

- Fasilitas Peribadatan : ada 5 masjid dan 10 musholla.

- Fasilitas Olah Raga : Iapangan sepak bola.

- Fasilitas Perdagangan : toko penjual kerajinan kerang, kerupuk, ikan asin, ikan bakar, wartel, toko dan warung kopi.

- Ada fasilitas jaringan PDAM, jaringan drainase kota; listrik dan Telkom.

- Fasilitas Kesehatan : ada Puskesmas di Kantor Kelurahan Kenjeran.

- Fasilitas Pendidikan : Taman Kanakkanak, Sekolah Dasar Negeri.

- Fasilitas Perkantoran : ada Balai RW.

- Fasilitas : Pool Sampah; pakir becak.

- Fasilitas Rekreasi : Taman Rekreasi Kenjeran

e. Aspek Lokasi :

- Di lokasi Kelurahan Kenjeran ada fasilitas jalan raya yang dilewati oleh beberapa angkutan umum dengan berbagai tujuan.

- Pencapaian ke lokasi pendidikan, Rumah Sakit, Perdagangan dan fasilitas di pusat kota cukup mudah.

\section{f. Aspek Lingkungan :}

\section{- Lingkungan Alam}

Kondisi tanahnya datar dan cukup kering. Ruang terbuka hijau sangat kurang. Udara panas dan ada polusi bau amis. Kondisi air tanah kurang baik, sehingga masyarakat cenderung memakai fasilitas air bersih PDAM, karena air sumur sekarang rasanya sudah agak asin dan keruh. 
- Lingkungan Buatan

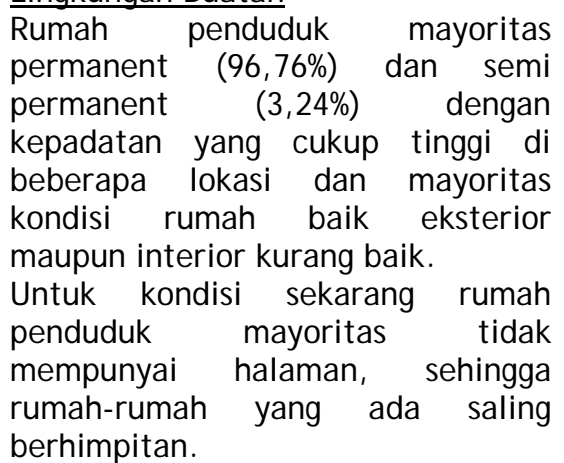

\subsection{WILAYAH ADMINISTRASI}

Kelurahan Kenjeran terdiri atas 5 RW dan 17 RT, dimana sebagian wilayah RW V adalah wilayah Perumahan Pantai Mentari yang dibangun oleh pengembang. Sedangkan untuk wilayah kampung di RW I,II adalah kampung dengan tipologi khas sebagai kampung nelayan, sedangkan RW III dan IV kebanyakan adalah pendatang yang bermata pencaharian sebagai tukang atau swasta. Wilayah-wilayah RW tersebut terbagi menjadi beberapa RT dengan perincian sebagaimana tersusun dalam table sebagai berikut :

Tabel 5.1. Wilayah Administrasi RW di Kelurahan Kenjeran

\begin{tabular}{|c|c|c|}
\hline RW & RT & J UMLAH \\
\hline I & $1,2,3,4,5$ & 5 \\
\hline II & $1,2,3$ & 3 \\
\hline III & 1,2 & 2 \\
\hline IV & $1,2,3$ & 3 \\
\hline V & $1,2,3,4$ & 4 \\
\hline \multicolumn{2}{|c|}{ J UMLAH } & $\mathbf{1 7}$ \\
\hline \multicolumn{2}{|c|}{}
\end{tabular}
2003

\section{HASIL DAN PEMBAHASAN}

Program-program bantuan yang diberikan pada permukiman kumuh di Kelurahan Kenjeran adalah sebagai berikut :

Tujuan Program KIP (Pelita I,II) adalah untuk meningkatkan kualitas lingkungan permukiman kampung melalui aspek fisik (prasarana dan sarana). Selanjutnya pada Program KIP (Pelita III) dan JPS., terjadi peningkatan bantuan; yaitu selain meningkatkan kualitas melalui aspek fisik juga meningkatkan kondisi sosial ekonomi masyarakatnya.

Pada Program KIP Komprehensif (1998, 2000, 2002,2003); yaitu merupakan salah satu upaya peningkatan kondisi perumahan dan permukiman kampung, dimana penanganannya dilakukan secara terpadu, baik dalam hal perbaikan fisik lingkungan, maupun kondisi sosial ekonomi masyarakat dilingkungan perkampungan tersebut. Berdasarkan lingkup kegiatan program yang ditangani, maka juga dilakukan dengan asas "TRI BINA PLUS" yaitu bina manusia, bina usaha, bina lingkungan yang sudah dikembangkan dengan menjadikan pola pembangunan kampung yang tidak sendiri tetapi sudah diintegrasikan pada system kota. Perbandingan antar bantuan program-program tersebut dapat dilihat pada pada table 6.1 dibawah ini 
TABEL 6. 1. PERBANDINGAN BANTUAN PROGRAM PEMBANGUNAN KAMPUNG DI KELURAHAN KENJ ERAN

\begin{tabular}{|c|c|c|c|c|c|}
\hline PROGRAM & ASAS & SASARAN & PELAKU & $\begin{array}{c}\text { KOMPONEN } \\
\text { PROGRAM }\end{array}$ & $\begin{array}{l}\text { KELEMBA- } \\
\text { GAAN }\end{array}$ \\
\hline $\begin{array}{l}\text { KIP } \\
\text { (Pelita } \\
I, \text { II) }\end{array}$ & $\begin{array}{l}\text { - Bina } \\
\text { Ling - } \\
\text { kungan }\end{array}$ & $\begin{array}{l}\text { Masyarakat } \\
\text { Berpenghasil- } \\
\text { an rendah }\end{array}$ & $\begin{array}{l}\text { - Badan Pelaksana } \\
\text { Proyek Perbaikan } \\
\text { Kampung (BP3K) } \\
\text { - Masyarakat } \\
\text { - Bank Dunia seba- } \\
\text { gai penyandang } \\
\text { dana }\end{array}$ & $\begin{array}{l}\text { - Perbaikan fi- } \\
\text { sik lingkung- } \\
\text { an (prasarana } \\
\text { dan sarana) }\end{array}$ & \\
\hline $\begin{array}{l}\text { KIP } \\
\text { (Pelita III) }\end{array}$ & $\begin{array}{l}\text { Tri Bina } \\
\text { - Bina } \\
\text { Manu - } \\
\text { sia } \\
\text { - Bina } \\
\text { Ling - } \\
\text { Kungan } \\
\text { - Bina } \\
\text { Usaha }\end{array}$ & $\begin{array}{l}\text { Masyarakat } \\
\text { menengah } \\
\text { Ke bawah }\end{array}$ & $\begin{array}{l}\text { - Badan Pelaksana } \\
\text { Pembangunan Pro } \\
\text { gram Perbaikan } \\
\text { Kampung } \\
\text { (Bappem KIP) } \\
\text { - Masyarakat } \\
\text { - Bank Dunia seba- } \\
\text { gai penyandang } \\
\text { dana }\end{array}$ & $\begin{array}{l}\text { - Perbaikan fi- } \\
\text { sik lingkungan } \\
\text { (prasarana } \\
\text { dan sarana) } \\
\text { - Pengembang- } \\
\text { an sumber da } \\
\text { ya manusia } \\
\text { - Pengembang- } \\
\text { an ekonomi } \\
\text { kampung }\end{array}$ & \\
\hline JPS & $\begin{array}{l}\text { Tri Bina } \\
\text { - Bina } \\
\text { Manu - } \\
\text { sia } \\
\text { - Bina } \\
\text { Ling - } \\
\text { Kungan } \\
\text { - Bina } \\
\text { Usaha }\end{array}$ & $\begin{array}{l}\text { Masyarakat } \\
\text { menengah ke } \\
\text { bawah }\end{array}$ & $\begin{array}{l}\text { - Konsultan seba- } \\
\text { gai pendamping } \\
\text { dan monitoring } \\
\text { - Masyarakat } \\
\text { - Pemerintah seba } \\
\text { gai fasilitator } \\
\text { - Bank Dunia seba } \\
\text { gai penyandang } \\
\text { dana }\end{array}$ & $\begin{array}{l}\text { - Perbaikan fi- } \\
\text { sik lingkung- } \\
\text { an (prasarana } \\
\text { dan sarana) } \\
\text { - Pengembang- } \\
\text { an sumber da } \\
\text { ya manusia } \\
\text { - Pengembang- } \\
\text { an usaha ke- } \\
\text { cil dan mene- } \\
\text { ngah }\end{array}$ & \\
\hline $\begin{array}{l}\text { KIP Kom- } \\
\text { prehensif } \\
\text { Tahun } \\
1998\end{array}$ & $\begin{array}{l}\text { Tri Bina } \\
\text { - Bina } \\
\text { Manu- } \\
\text { sia } \\
\text { - Bina } \\
\text { Ling- } \\
\text { kung- } \\
\text { an } \\
\text { - Bina } \\
\text { Usaha }\end{array}$ & $\begin{array}{l}\text { Masyarakat me } \\
\text { nengah ke ba- } \\
\text { wah }\end{array}$ & $\begin{array}{l}\text { - Konsultan seba - } \\
\text { gai pendamping } \\
\text { dan monitoring } \\
\text { - Masyarakat } \\
\text { - Pemerintah se- } \\
\text { bagai fasilitator } \\
\text { - Bank Dunia seba } \\
\text { gai penyandang } \\
\text { dana }\end{array}$ & $\begin{array}{l}\text { - Perbaikan fi- } \\
\text { sik lingkungan } \\
\text { - Peningkatan } \\
\text { kemampuan } \\
\text { masyarakat } \\
\text { - Manajemen } \\
\text { lahan } \\
\text { - Peningkatan } \\
\text { kualitas ru - } \\
\text { mah }\end{array}$ & $\begin{array}{l}\text { - Yayasan } \\
\text { Kampung } \\
\text { (YK) } \\
\text { - Koperasi } \\
\text { Serba Usa- } \\
\text { ha (KSU) } \\
\text { - Badan Koor } \\
\text { dinasi Ke - } \\
\text { lompok Swa } \\
\text { daya } \\
\text { (BKSW) } \\
\text { - Kelompok } \\
\text { Swadaya } \\
\text { Warga }\end{array}$ \\
\hline
\end{tabular}

Halaman 36 J urnal APLIKASI: Media Informasi \& Komunikasi Aplikasi Teknik Sipil Terkini 
TABEL 6.1 (lanjutan)

PERBANDINGAN BANTUAN PROGRAM PEMBANGUNAN KAMPUNG DI KELURAHAN KENJ ERAN

\begin{tabular}{|c|c|c|c|c|c|}
\hline PROGRAM & ASAS & SASARAN & PELAKU & $\begin{array}{c}\text { KOMPONEN } \\
\text { PROGRAM }\end{array}$ & $\begin{array}{l}\text { KELEMBA- } \\
\text { GAAN }\end{array}$ \\
\hline $\begin{array}{l}\text { KIP Kom - } \\
\text { prehensif } \\
\text { Tahun } \\
2000\end{array}$ & $\begin{array}{l}\text { Tri Bina } \\
\text { Plus } \\
\text { - Bina } \\
\text { Manu- } \\
\text { sia } \\
\text { - Bina } \\
\text { Ling- } \\
\text { kung- } \\
\text { an } \\
\text { - Bina } \\
\text { Usaha } \\
\text { - Plasma } \\
\text { kota }\end{array}$ & $\begin{array}{l}\text { Masyarakat me- } \\
\text { nengah ke ba- } \\
\text { wah }\end{array}$ & $\begin{array}{l}\text { - Konsultan seba- } \\
\text { gai pendamping } \\
\text { dan monitoring } \\
\text { - Masyarakat } \\
\text { - Pemerintah kota } \\
\text { sebagai fasilita- } \\
\text { tor dan penyan- } \\
\text { dang dana }\end{array}$ & $\begin{array}{l}\text { - Perbaikan fi- } \\
\text { sik lingkung- } \\
\text { an (prasarana } \\
\text { dan sarana) } \\
\text { - Pengembang } \\
\text { an sumber da } \\
\text { ya manusia } \\
\text { - Pengembang } \\
\text { an usaha kecil } \\
\text { dan mene - } \\
\text { ngah } \\
\text { - Perbaikan ru- } \\
\text { mah }\end{array}$ & $\begin{array}{l}\text { - Yayasan } \\
\text { Kampung } \\
\text { (YK) } \\
\text { - Koperasi } \\
\text { Serba Usa- } \\
\text { ha (KSU) } \\
\text { - Kelompok } \\
\text { Swadaya } \\
\text { Warga } \\
\text { (KSW) }\end{array}$ \\
\hline $\begin{array}{l}\text { KIP Kom- } \\
\text { prehensif } \\
\text { Tahun } \\
2002\end{array}$ & $\begin{array}{l}\text { Tri Bina } \\
\text { Plus } \\
\text { - Bina } \\
\text { Manu- } \\
\text { sia } \\
\text { - Bina } \\
\text { Ling- } \\
\text { kung- } \\
\text { an } \\
\text { - Bina } \\
\text { Usaha }\end{array}$ & $\begin{array}{l}\text { Masyarakat me } \\
\text { nengah ke ba - } \\
\text { wah }\end{array}$ & $\begin{array}{l}\text { - Konsultan seba- } \\
\text { gai pendamping } \\
\text { dan monitoring } \\
\text { - Masyarakat } \\
\text { - Pemerintah kota } \\
\text { sebagai fasilita- } \\
\text { tor dan penyan- } \\
\text { dang dana }\end{array}$ & $\begin{array}{l}\text { - Perbaikan fi- } \\
\text { sik lingkungan } \\
\text { (prasarana } \\
\text { dan sarana) } \\
\text { - Penghijauan } \\
\text { - Pengembang } \\
\text { an sumber da } \\
\text { ya manusia } \\
\text { - Pengembang } \\
\text { an usaha ke - } \\
\text { cil dan mene- } \\
\text { ngah } \\
\text { - Perbaikan ru- } \\
\text { mah }\end{array}$ & $\begin{array}{l}\text { - Yayasan } \\
\text { Kampung } \\
\text { (YK) } \\
\text { - Koperasi } \\
\text { Serba Usa- } \\
\text { ha (KSU) } \\
\text { - Kelompok } \\
\text { Swadaya } \\
\text { Warga } \\
\text { (KSW) }\end{array}$ \\
\hline $\begin{array}{l}\text { KIP Kom- } \\
\text { prehensif } \\
\text { Tahun } \\
2003\end{array}$ & $\begin{array}{l}\text { Tri Bina } \\
\text { Plus } \\
\text { - Bina } \\
\text { Manu- } \\
\text { sia } \\
\text { - Bina } \\
\text { Ling - } \\
\text { kung- } \\
\text { an } \\
\text { - Bina } \\
\text { Usaha }\end{array}$ & $\begin{array}{l}\text { Masyarakat me- } \\
\text { nengah ke ba- } \\
\text { wah }\end{array}$ & $\begin{array}{l}\text { - Konsultan se - } \\
\text { bagai pendam- } \\
\text { ping dan moni- } \\
\text { toring } \\
\text { - Masyarakat } \\
\text { - Pemerintah ko- } \\
\text { ta sebagai Fasi- } \\
\text { litator dan pe - } \\
\text { nyandang dana }\end{array}$ & $\begin{array}{l}\text { - Perbaikan fi- } \\
\text { sik lingkungan } \\
\text { (prasarana } \\
\text { dan sarana) } \\
\text { - Penghijauan } \\
\text { dan Kebersih- } \\
\text { an lingkung- } \\
\text { an } \\
\text { - Pengembang- } \\
\text { an usaha ke- } \\
\text { cil dan mene } \\
\text { ngah } \\
\text { - Perbaikan ru- } \\
\text { mah }\end{array}$ & $\begin{array}{l}\text { - Yayasan } \\
\text { Kampung } \\
\text { (YK) } \\
\text { - Koperasi } \\
\text { Serba Usa- } \\
\text { ha (KSU) } \\
\text { - Kelompok } \\
\text { Swadaya } \\
\text { Warga } \\
\text { (KSW) }\end{array}$ \\
\hline
\end{tabular}

Sumber : Laporan Akhir Kegiatan KIP. Komprehensif - 2003

\subsection{PREMIS-PREMIS KEMITRAAN}

Terdapat persamaan tema antara GSS (Global Strategy forShelter) yang disusun pada tahun 1990 di Nairobi, dengan Deklarasi dan Agenda Habitat II yang dirumuskan pada tahun 1996 di Turki.
Konsep Kemitraan perlu ditekankan sebagai salah satu konsep unggulan. Penekanan ini pada Deklarasi Istambul (Habitat II) nomor 12 yang menyatakan :

We adopt the enabling strategy and the principles of partnership and participation 
as the most democratic and effective approach for the realization of our commitments.. We shall also increase our cooperation with parliamentarians, the private sector, labour unions and nongovernmental and other civil society organizations with due respect for their autonomy...(UNCHS, 1996:9).

Dari Report of United Nations Conference on Human Settlements (Habitat II), bahwa konsep kemitraan untuk segera dilaksanakan guna menunjang pembangunan. Pernyataan tersebut termuat didalam mukadimah (preamble) nomor 5 :

...The sooner communities, local governments and partnership among the public, private and community sectors join efforts to create comprehensive, bold and innovative strategies for shelter and human settlements, the better the prospects will be for the safety, health and well-being of people and the brighter the outlook for solutions to global environment and social problems (Ibid, p. 13).

Pada bagian lain yang merumuskan tujuan dan prinsip dari operasional mengenai kemitraan :

“Partnership among countries and among all actors within countries from public, private, voluntary and community-based organizations, the cooperative sector, non governmental organizations and individuals are assential to the achievement of sustainable human settlements development and the provision of adequate shelter for all and basic services. Partnerships can integrate and mutually support objectives of broadbased participation through, inter alia, forming alliances, pooling resources, sharing knowledge, contributing skills and capitalizing on the comparative advantages of collective actions. The processes can be made more effective by strenghthening civil organization and partnership of all sectors of society and among all actors in decision-making processes, as appropriate" (Ibid, p.20).
Apabila kita menyimak premis-premis dan pelaksanaan bantuan-bantuan program diatas, nampak adanya beberapa issue yang perlu mendapatkan perhatian. Isueisue tersebut adalah :

1. Isue - 1: "Gap"

Pentingnya konsep Kemitraan untuk menjembatani gap antara sector pemerintah dan swasta, dan antara kepentingan komersial dan kepentingan masyarakat. Dengan demikian memang telah diakui oleh UNCHS (United Nations Conference on Human Settlements), bahwa terdapat gap antara sector-sektor pemerintah dan swasta.

\section{Isue - 2: "Hubungan antar Aktor"}

Pentingnya hubungan antar-aktor yang ditekankan oleh Habitat II, yakni antara Publik atau pemerintah, Swasta, Masyarakat, dan Mediator, adalah :

- Voluntary organizations

- Community Based Organizations

- Cooperative

- Non Government Organization

- Individuals

\section{Isue - 3: "Tujuan Esensial"}

Adanya tujuan esensial yang ingin dicapai oleh konsep kemitraan, yakni : Adequate shelter for all, and sustainable human settlements.

\section{Isue - 4: "Komunikasi" dan "Informasi"}

Pentingnya komunikasi dan informasi sebagai tulang punggung kemitraan

\section{Isue - 5: "Strategi"}

Adanya strategi bagi operasionalisasi konsep kemitraan, yang berupa :

- Forming alliances

- Pooling resources

- Sharing knowledge

- Contributing skills, dan

- Capitalizing on the comparative advantages of "collective action"

Kemudian kelima isu tersebut dibawa kedataran paradigmatic, dengan tujuan agar kekuatan dan kelemahan dari kelima 
konsep tersebut dapat dibaca secara lebih jernih. Dua paradigma yang akan dipakai untuk membaca kelima konsep tersebut adalah : (1) paradigma convivialist, dan (2) paradigma radicalist.

$\underline{\text { Isue - } 1 \text { : "Gap" }}$

Menurut kaum convivialist, "gap" atau kesenjangan merupakan sesuatu yang alamiah.

Bagi pemerintah, pembangunan untuk masyarakat miskin, merupakan suatu tugas yang tidak dapat dielakkan. Sebaliknya, bagi swasta pembangunan merupakan suatu Iahan ekonomi yang menjanjikan keuntungan besar yang cepat diraih, sehingga kelompok sasarannya adalah kelompok elit. Dengan demikian, bagi kaum convivialist, komunikasi merupakan infrastruktur yang penting untuk menjembatani kesenjangan-kesenjangan tersebut. Kesenjangan, dapat diatasi melalui rekayasa komunikasi.

Sebaliknya, bagi kaum radicalist, kesenjangan merupakan suatu kesengajaan yang dibuat oleh kekuasaan, sehingga hal ini merupakan suatu persoalan structural. Dengan demikian pemerintah harus melakukan kendali penuh (full control) terhadap pembangunan, agar tidak menjadi ajang spekulasi dan komoditisasi.

$\underline{\text { Isue - 2: "Hubungan Antar-Aktor" }}$

Dalam pandangan radicalist, hubungan antara pemerintah, swasta, dan masyarakat cenderung mengikuti pola hierarkis. Pola hubungan yang terjadi adalah bukan kesetaraan, melainkan merupakan hubungan antara superior dan inferior. Bentuk hubungan yang terjadi lebih bersifat command dan instruction, bahkan kadang-kadang terjadi hubungan yang cenderung power approach. Dalam pemahaman ini, pembangunan tidak memihak kepada kepentingan rakyat terbanyak, melainkan memihak kepada kepentingan pemerintah dan komersial.

Sebaliknya, bagi kaum convivialist, hubungan antara pemerintah, swasta, masyarakat, dan mediator (NGO, dan sebagainya), dilihat sebagai hubungan yang rekonsiliatif. Hubungan terjadi karena masing-masing memiliki peran khusus dan masing-masing tetap dihormati otonominya. Di dalam hubungan ini tidak terjadi dominasi satu terhadap lainnya dan semua actor memiliki peran dan sumbangan yang spesifik bagi pembangunan.

\section{$\underline{\text { Isue - 3: "Tujuan Esensial" }}$}

Tujuan esensial dari agenda Habitat II ada dua, yakni terciptanya : (1) adequate shelter for all, dan (2) sustainable development.

Di dalam pandangan kaum radikalis, konsep sustainable development merupakan suatu romantisme dari Negaranegara kapitalis terhadap negara-negara berkembang.

Sedangkan, kaitannya dengan tujuan adequate shelter for all, menurut pandangan radicalist, karena layak disini tidak diukur dari nilai-nilai manusiawi, melainkan diukur dari nilai-nilai ekonomi, terutama dalam kaitannya dengan alasan keterbatasan keuangan pemerintah.

Sebaliknya, kaum convivialist berpandangan, bahwa konsep sustainable development merupakan suatu kendaraan dunia yang tidak dapat dielakkan lagi oleh setiap Negara, wilayah, komunitas, maupun individu. Tidak ada satupun individu dapat menghindar dari tanggung jawabnya terhadap keberlanjutan lingkungan hidup manusia.

Sedangkan mengenai tujuan adequate shelter for all, para convivialist berpandangan , karena layak memang relative dan kontekstual, maka kondisi layak merupakan kondisi yang selalu berubah pada arah yang lebih baik. Dalam situasi keterbatasan dana yang dimiliki oleh pemerintah, maka pengertian layak tidak harus semuanya tersedia dan terpenuhi.

Isue - 4: "Komunikasi" dan "Informasi"

Dalam pandangan kaum radicalist, komunikasi mengajak masyarakat menjadi kritis terhadap realita sosial yang ada dihadapan mereka, namun juga kritis terhadap nilai-nilai baru yang mencoba memasuki kehidupan mereka. Dalam 
konteks pembangunan perumahan, harus dihindarkan dari segala bentuk komunikasi dan hubungan yang hierarkikal (berjenjang), karena bentuk komunikasi semacam ini cenderung, menciptakan bentuk-bentuk eksploitasi. Pembangunan perumahan harus diarahkan pada terciptanya suatu lingkungan yang harmonis (komunikatif-hubungan timbal balik), serta mengajarkan prinsip-prinsip kerjasama saling menguntungkan, menghindari bentuk-bentuk komunikasi atau hubungan yang cenderung kompetitif.

Sebaliknya, bagi kaum convivialist, komunikasi cenderung lebih dilihat dari kacamata pragmatisme. Komunikasi diterjemahkan kedalam model social learning atau belajar bersama. Dalam model ini, masyarakat, pemerintah, swasta, dan mediator (individu, NGO dan sebagainya) belajar bersama-sama. Fokus utama dari social learning ini adalah tindakan nyata yang bertujuan oleh suatu kelompok masyarakat.

Isue - 5: "Strategi"

Dalam pandangan kaum radicalist, itemitem dari strategi tersebut harus disikapi secara kritis, jangan sampai justru membelenggu gerak dinamis masyarakat yang cenderung mematikan inisiatif masyarakat. Semua item dari strategi tersebut harus memiliki jiwa memihak kepada masyarakat, membawa masyarakat secara emansipatif mencapai tujuannya yang rasional, yakni tujuan yang dirumuskan secara bersama dengan penuh kepahaman dan kesadaran; bukan tujuan yang dimanipulasikan.

Sebaliknya, menurut pandangan kaum convivialist, nampaknya item-item dari strategi tersebut lebih cenderung disikapi secara pragmatic, sehingga item-item strategi kemitraan tersebut diatas memang diperlukan untuk memperlancar proses

menghindar dari tanggung jawabnya terhadap keberlanjutan lingkungan permukimannya.

3. Pergeseran posisi pelaku utama dari pemasok (pemerintah dan swasta) ke pembangunan yang berpihak pada kepentingan masyarakat.

Dari program-program bantuan yang telah diberikan masih banyak tantangan yang perlu diperhatikan yaitu tuntutan adanya perubahan visi warga dari dirinya yang semula dilayani (obyek) menuju ke warga sebagai pelaku (subyek) pembangunan dari perbaikan lingkungan permukimannya. Jadi kelima issue dari premis-premis kemitraan sangat relevan untuk mengatasi tantangan tersebut diatas, terutama menurut pandangan kaum convivialist; adalah sebagai berikut :

1. Kesenjangan dapat diatasi melalui rekayasa komunikasi.

2. Hubungan antara pemerintah, swasta, masyarakat, dan mediator, dilihat sebagai hubungan rekonsiliatif.

3. Bahwa tidak ada satupun individu dapat menghindar dari tanggung jawabnya terhadap keberlanjutan lingkungan hidup manusia.

4. Bahwa komunikasi diterjemahkan kedalam model social learning atau belajar bersama.

5. Bahwa item-item strategi kemitraan tersebut diatas memang diperlukan untuk memperlancar proses pembangunan yang berpihak pada kepentingan masyarakat.

\section{KESIMPULAN DAN SARAN}

\subsection{KESIMPULAN}

1. Didalam Pola Kemitraan kesenjangan dapat diatasi melalui rekayasa komunikasi; yakni hubungan antara pemerintah, swasta, masyarakat, dan mediator, dilihat sebagai hubungan rekonsiliatif.

2. Didalam Pola Kemitraan, bahwa masalah lingkungan permukiman tidak berdiri sendiri, melainkan terikat didalam kesadaran pembangunan lingkungan yang lebih luas dan tidak ada satupun individu dapat masyarakat. Hal ini berarti masyarakatlah yang menentukan apa yang perlu dan bagaimana harus dipasok dalam pembangunan lingkungan permukimannya. 


\section{ISSN. 1907-753X}

\subsection{SARAN}

Agar pola kemitraan dapat berjalan sesuai dengan harapan, maka kedudukan mediator (planner) melibatkan diri secara intens dan belajar bersama-sama masyarakat, pemerintah dan swasta. Planner harus membuat pencingan strategi atau taktik menuju upaya perubahan, tujuannya agar terjadi komunikasi antara planner dan masyarakat untuk memancing permasalahan-permasalahan yang lebih luas lagi yang masih terpendam didalamnya.

\section{DAFTAR PUSTAKA}

Badan Pusat Statistik Kota Surabaya 92002), Kota Surabaya Dalam angka, BPS. Kota Surabaya.

Devas, Nick, "Indonesia's Kampung Improvement Programme An Evaluative Case-Study". Development Administration Group, Institute of Local Government Studies, University of Birmingham, 1980.
Kartono, Kartini (1996), Pengantar Metodologi Riset Sosial, Penerbit Mandar Maju.

Laquian, Aprodicio A, "Whither Site and Services". Habitat International Vol.2,No.3/4, pp. 291-301, 1977.

Leeds, A, "Lower Income Settlement Types:Process, Structures, Policies, in UNCHS: The Resdential Circumstanes of The Poor In Developing Countries", pp. 21-61, New York: Praeger, 1981.

Pemerintah Kota Surabaya Dinas Tata Kota, "Laporan Akhir Kegiatan Pelaksanaan KIP Komprehensif Kelurahan Kenjeran Kecamatan Bulak", Tahun 2003.

Sudaryono, Suryanto, Marsoyo, A, Tjokrosoedarmo, S, Giyarsih, S.M, Riyanto dan Effendi, T.N.(1996), "Prospek Rumah Sangat Sederhana (RSS) Sebagai Strategi Pemecahan Masalah Perumahan Para Miskin Kota Pada PJ P II", Laporan Akhir, Riset 
